\title{
An Educational Program on Produce Food Safety/Good Agricultural Practices for Small and Limited Resource Farmers: a Case Study
}

\author{
Barrett Vaughan, Ph.D. \\ Associate Professor \\ College of Agriculture, Environment, and Nutrition Sciences \\ Tuskegee University \\ Henderson Hall \\ Tuskegee, Alabama U.S.A. 36088
}

\begin{abstract}
The educational methods used in a food safety/Good Agricultural Practices (GAP) educational program with small and limited resource produce farmers in Alabama to assist them with obtaining certification were examined in this case study. The educational methods enlisted to facilitate food safety certification included group meetings, instructional material delivery, individual farm instruction, and expert instruction. In addition, there were four challenges to food safety certification identified - the needs for motivation, information, clarification, and resources-along with strategies to address the challenges. The program was found to be limitedly successful, producing ten GAP-certified operations. It was concluded that further evaluation of the educational methods is needed.
\end{abstract}

Keywords: Small farms, Food Safety, Certification, Good Agricultural Practices, Produce

\section{Introduction}

In most cases, food safety/Good Agricultural Practices (GAP) certification is a requirement for selling produce to larger commercial markets. State government and educational outreach units undertake efforts to prepare farmers for certification that are intended to deliver the required knowledge on critical areas such as worker health and hygiene, water quality, animal management, and record keeping. These food safety training efforts, however, must be tailored to address the particular needs of the farm managers and their workers (Kline et al., 2012; Mathiasen et al., 2012; Nolte et al., 2011). In fact, one study has shown that having certification is likely to soon be necessary for supplying all commercial markets (Tobin et al., 2011). This case study examined an educational program and the outcomes in terms of farm certification. Prior studies with small and limited resource and minority farmers have established that outreach efforts require the discovery of "what steps should be taken toward providing viable information and services" (Marshall, 2012). This study documents the steps taken in one such effort where there was an immediate need for the farmers to have food safety certification.

\section{Background}

\subsection{Food Safety and Commercial Markets}

Suppliers are required to adhere to commercial level standards in order to supply produce to most commercial buyers. The standards apply to elements such as packaging, insurance, logistics, and food safety. The food safety standards make sure that the produce is grown and handled using practices where the contamination risks are reduced. Also, the standards reduce the potential legal liabilities from food-borne illness outbreaks. The commercial buyer has the responsibility to make sure that the produce that the consumer is purchasing is "safe." To certify that farming activities and procedures reduce the risk of contamination, different sets of criteria have been developed. These criteria govern nearly every facet of production including worker hygiene and training, equipment use and maintenance, purchasing of planting materials and chemicals, transportation, and harvesting and storage. These criteria emphasize the adoption and maintenance of these activities and procedures, and record keeping with the traceability of all produce supplied to the commercial buyer. These sets of criteria are known as Good Agricultural Practices (GAP). 


\subsection{Food Safety/GAP Certification}

The service of auditing the activities and procedures at a farm by a particular set of GAP criteria-to determine whether a farm is properly implementing GAP - is offered by third-party organizations (i.e., not the supplier and not the farmer). A detailed inspection of the farm and the harvesting and handling of produce, interviews of workers to gauge their food safety knowledge, and a rigorous review of the records are included in this audit. The audit is passed where it verifies that the farm has adopted and maintained those activities and procedures that reduce the risk of contamination. When an audit is passed, a certification is conferred upon the farm, i.e., the farm is "Food Safety-Certified" or "GAP-Certified."

Commercial buyers are assured by the food safety certification that the risk of contamination has been minimized by the manner that the produce has been grown, harvested, and handled. Certification demonstrates that the farm has made a commitment to provide produce that is safe. In fact, commercial buyers may food safety certification as important as liability insurance.

\subsection{GAP Certification and Audit Preparation}

There are a number of major adjustments that must be made for any farm to prepare for food safety certification. The activities and procedures to be modified concern almost all aspects of the farm; therefore, it can be said that, 'food safety is not just an aspect of the operation, it is the operation." Many medium and large farmers find the preparation for an audit a daunting task; the task can seem insurmountable for many small and limited resource farmers. For food safety certification, records must be kept of nearly all farm activities. Unfortunately, many small and limited resource farms do not have personnel specifically for this task. A key component to keeping food safe is worker training and hygiene. However, at a small or limited resource farm, the cost to provide training and facilities represent a significant expense. For any, farm, large, medium, or small, the changes, monitoring, and maintenance of the fields and grounds are extensive and often costly in time, wages, and equipment use. As a result, due to the circumstances of most small and limited resource farms and the nature of the food safety standards, supplying to a commercial market has been unattainable to these farmers up until this time.

\section{Methods}

\subsection{Data Collection and Analysis}

A standard method for case study analysis was not used in this study. An organized documentation of the measures taken in the effort to assist the farmers to become food safety / GAP certified is presented here; however, a study of these efforts was not explicit intended. The educational measures that were taken evolved as the project progressed to better facilitate the preparation for certification. In the process, the challenges to certification and development of strategies to address the challenges were identified and chronicled. An outreach staff member was assigned to directly assist each farm in the program to gather this information which was collected from their notes of meetings with the farmer and from meetings of the outreach staff over the period of the growing season in 2013.

\subsection{Educational Methods}

The educational methods used in the effort to assist the farms to obtain food safety certification were various. The plan for implementing the GAP educational program included mainly large group trainings, initially. Other methods were added as the program progressed to provide updated or more readily understandable information as well as to address the challenges presented by the farmers. The educational methods employed can be grouped into four modes: group instruction, instructional materials delivery, individual farm instruction, and expert instruction.

\subsubsection{Group Instruction}

The methods of group instruction included large group training, small group meetings, and weekly telephone conference calls. Large group trainings consisted of twenty to thirty attendees from about a dozen farms. Videos, presentations, and handouts from the USDA National Good Agricultural Practices (GAPs) Program located at Cornell University were used as the training materials. Crop-specific factsheets and other instructional materials complemented these materials. Small group meetings focused on particular training needs such as worker health and hygiene and record keeping and normally consisted of a dozen or fewer attendees. 
Between three and thirty participants, including farm personnel and program staff, took part in the weekly conference calls which were held in the early morning. These calls acted as regular "question and answer" forum and a variety of topics were discussed. These methods of group instruction were the primary means of delivering general food safety and program information.

\subsubsection{Instructional Materials Delivery}

A set of instructional materials was developed and delivered at the trainings and meetings or by electronic means to complement the group instruction methods. The instructional materials offered more detailed instruction than the materials from the National GAPs Program and were created to further assist the farms to implement the food safety activities and procedures. The materials "filled in the gaps" remaining from the other educational methods. The primary instructional material developed was a Standard Operating Procedures (SOP) template; it was also known as "the plan." The process of developing of the plan template was iterative; as more information and feedback was received from experts in the industry, auditors, outreach personnel, and farmers, improvements were made. Other materials developed to complement the plan template included a start-up guide with instruction on pre-season assessments and activities, a quick reference guide for record keeping, and a pre-audit checklist for preparing the plan, fields, and workers.

\subsubsection{Individual Farm Instruction}

The group instruction sessions and instructional materials delivery were found to be inadequate in assisting the farms to prepare for food safety certification. Individual farm instruction was therefore deemed to be necessary for program success. Each of the farms was assigned a specific outreach staff member as their program liaison and contact person in order to assist in the certification process. Guiding the farms in developing their plan was the primary function of the individual farm instruction which was done in plan consultations. Two sessions with the farm were typically necessary. The first session was for gathering the information to customize the plan template for their operation. The second was for going over the plan and the record keeping duties with the farmer. Another set of two to three sessions was necessary to review the plan for completeness and to assist farmers with gathering any missing information before the certification audit. Also, to determine the readiness of the fields for the audit, farm visits were conducted by outreach staff. A mock audit was conducted by outreach staff in some cases.

\subsubsection{Expert Instruction}

Expert instruction, that is, the connection of food safety experts in the industry to the farms, was the other mode. The farms were provided with information from, interaction with, and real feedback on the progress that they were making from buyers and auditors through the expert instruction. Also, the food safety auditors were enlisted to conduct educational audits - actual, paid audits that did not count against the operation-in advance of the certification audit. Several buyer companies volunteered their food safety experts to tour and review farms, inspect fields, and answer questions about food safety compliance. The visits were invaluable in providing the industry's perspective on food safety and its importance to the farms. Also, tours were arranged for the program farmers to see large, commercial operating farms out-of-state and their food safety activities and procedures.

\section{Results}

In the 2013 season, these various efforts produced the certification a total of nine farms and one processing facility. Fifteen audits were approved or passed by these nine farms because some farms were audited for summer and fall crops. USDA Produce GAPs Harmonized Food Safety Standard Audit was the program that the farms were certified. They were also approved under the Global Markets Primary Production Assessment. This supplemental assessment was a set of optional additional questions beyond the Harmonized Audit. The Global Markets Addendum was required by the commercial buyer for all suppliers. The certified farms were all approved for both audits. About half of the certified farms were able to supply produce to a large commercial buyer, beginning in August, although many crop failures were seen in the 2013 season. The crops supplied were from replanted fields in most cases. Unfortunately, many of the certified farms lost most of their crop. There was barely enough to ship commercially but enough to harvest for an audit. The certified farms that lost their crops, however, were able to carry their certification into the fall crops over or into next year's summer season. Through this educational endeavor, relationships with the USDA Agricultural Marketing Service Audit Division were also developed. AMS staff from Washington, DC visited to discuss the certification program and observe the audits. 
Relationships with the staff of the Alabama Department of Agriculture and Industries Audit Division were also created. The formation of these relationships was invaluable to the success of the farmers in obtaining certification.

\section{Discussion - Challenges and Strategies}

Various challenges were addressed while assisting these farmers in the process of becoming food safety certified. A number of challenges were presented with each farm depending on the circumstances. The various challenges were classified into four categories of needs: motivation; information; clarification, and; financial resources. The nature and remedy for the challenges are very similar, although each in a category may arise from different circumstances.

\subsection{Motivation}

The need for motivation involves beliefs held by a farm that hinder the progress in adopting food safety practices. Challenges related to motivation include a resistance to change in agriculture, a resistance to make long-term changes in the operation, and a perceived lack of fairness in the food safety requirements in the commercial market. Regardless of size, all farms that are not supplying to commercial markets will experience these challenges to some degree. To deal with these challenges, the primary strategy is the presentation of the short- and long-term benefits of supplying to commercial markets to encourage the farmers.

\subsection{Information}

The need for information entails either a lack of access to information, a lack of skills to assimilate the knowledge presented, or a lack of conditions that promote or permit the sharing of knowledge or training. Challenges related to information include a lack of access to educational resources on food safety, literacy and, in some cases, ESL (English as a Second Language) issues, and a transient or otherwise inconsistent labor pool. Depending on the personnel resources available to the farm, these challenges are very farm-specific. With these challenges, the strategy to overcome these deficiencies is to supply the farm with access to information, assistance, or materials that will help them.

\subsection{Clarification}

The need for clarification comes from a preponderance of misinformation, not from a lack of information. Challenges related to clarification include a resistance to change in understanding of the potential for contamination, a lack of regarding the importance record keeping, and not fully considering the benefits and costs, that is, doubting the worth of certification. These types of challenges would be present with many farms. The strategy used with these challenges, along with providing valid information, is making an argument for adopting the food safety practices and for supplying commercial markets.

\subsection{Financial Resources}

The need for financial resources pertains to the expenses related to adopting food safety practices. The challenges include a lack of funds for making necessary changes to the farm activities and procedures, a lack of resources for record keeping personnel and food safety management, and a lack of funds for the audit. At small and limited resource farms, these challenges are naturally common, by definition. Helping the farm to eliminate unnecessary costs, reduce direct costs, and access additional funding is the strategy to address these challenges.

\section{Conclusion}

In conclusion, where the challenges to certification were adequately addressed the efforts to assist these small and limited resource farmers to become food safety / GAP certified were successful. The challenges were common to most small and limited resource farmers, but for most of the farmers were not insurmountable. It was necessary to accurately assess the capability and situation of the farmer and adapt and utilize the educational method that will be most effective; this was the most important lesson learned. In the future, it will be necessary to ascertain the relative effectiveness of the educational methods used and the strategies in a much more scientific way. Determining the most appropriate methods for future seasons would be assisted by such a study. This study, by contrast, offered a qualitative insight into the educational methods suitable for food safety/GAP outreach to small and limited resource farmers and challenges faced. 


\section{References}

Kline, T.R., H. Kneen, E. Barrett, A. Kleinschmidt, and D. Doohan. (2012). "Adapting Extension Food Safety Programming for Vegetable Growers to Accommodate Differences in Ethnicity, Farming Scale, and Other Individual Factors.” Journal of Extension 50 (1). http://www.joe.org/joe/2012february/iw1.php [Retrieved November 20, 2018].

Marshall, R.W. (2012)."The Impact of the Extension Service on Minority-Owned Small Farm Operations." Journal of Extension 50 (1). http://www.joe.org/joe/2012february/comm1.php [Retrieved November 20, 2018]

Mathiasen, L., K. Morley, B. Chapman, and D. Powell. (2012). "Using a Training Video to Improve Agricultural Workers' Knowledge of On-Farm Food Safety.” Journal of Extension 50 (1). http://www.joe.org/joe/2012february/a6.php [Retrieved November 20, 2018].

Nolte, K.D., C.A. Sanchez, J.M. Fonseca. (2011). "Assessing the Culture of Fresh Produce Safety Within a Leafy Green Producing Community." Journal of Extension 49 (6). http://www.joe.org/joe/2011december/iw4.php [Retrieved November 20, 2018].

Tobin, D, J, Thomson, L. LaBorde, and J. Bagdonis. (2011). "Developing GAP Training for Growers: Perspectives from Pennsylvania Supermarkets." Journal of Extension 49 (5). http://www.joe.org/joe/2011october/rb7.php [Retrieved November 20, 2018]. 